Hassel, D. van, Coops, A., Batenburg, R., Heus, P. Een meting van het substitutiepotentieel binnen de oogzorg. TSG: Tijdschrift voor Gezondheidswetenschappen: 2013, 91(8), 497-504

\begin{tabular}{|l|l|}
\hline $\begin{array}{l}\text { Postprint } \\
\text { Version }\end{array}$ & 1.0 \\
\hline Journal website & http://link.springer.com/article/10.1007\%2Fs12508-013-0161-x \\
\hline Pubmed link & \\
\hline DOI &
\end{tabular}

This is a NIVEL certified Post Print, more info at http://www.nivel.eu

\title{
Een meting van het substitutiepotentieel binnen de oogzorg
}

\section{DAniël Hassel, Annemieke CoOps, Ronald Batenburg, Pauline Heus}

In recent years tasks reallocation between professions within Dutch eye care has been gaining importance in health policy, due to a higher demand for medical care and increasing financial costs. Empirical research focusing on the (potential) role of optometrists concerning task substitution barely exists, however. The aim of this study is to indicate the 'substitution potential' of optometrists within the eye care system. Based on patient-data of optometrists and general practitioners we estimated the substitution potential for a number of eye diseases. These diseases were judged as 'substitutable' according to two ophthalmologists and four optometrists. Results show that an annual shift of up to 207,000 general practitioner patients to the optometrist is possible, and up to 21,000 ophthalmologist patients can be prevented in case general practitioners refer patients with eye problems to the optometrist instead of the ophthalmologist. Our analysis estimated the potential pivotal volume taking by optometrists through task substitution within Dutch eye care. Results need to be interpreted carefully, however. A number of limitations have to be taken into account: (1) the list of potential substitutable' eye diseases was assessed by only six experts, and (2) statistics on a limited number of eye diseases were available or comparable in datasets of general practice and optometrist practices. This study primarily provides a conceptual method to explore what volumes optometrists can attribute to task substitution within the Dutch eye care system.

\section{INLEIDING}

Taakherschikking in de gezondheidszorg wordt steeds relevanter en staat hoog op de beleidsagenda van de overheid. Een veel geciteerde definitie van taakherschikking is dat taken structureel en formeel herverdeeld worden binnen een beroepsgroep of tussen verschillende beroepsbeoefenaren van een beroepsgroep.1,2 Voorbeelden van taakherschikking zijn te vinden binnen de eerstelijns zorg waar de fysiotherapeut taken van de huisarts is gaan overnemen 3,4 of waar de mondhygiënist taken van de tandarts is gaan uitvoeren.5,6,7 Ook binnen de Nederlandse oogzorg, waar al lange tijd een tekort aan oogartsen dreigt,8,9,10 zouden tweedelijns optometristen taken geheel of gedeeltelijk kunnen overnemen van oogartsen.11 Een mogelijkheid die steeds meer geopperd wordt om beter te kunnen voldoen aan de toenemende 
Hassel, D. van, Coops, A., Batenburg, R., Heus, P. Een meting van het substitutiepotentieel binnen de oogzorg. TSG: Tijdschrift voor Gezondheidswetenschappen: 2013, 91(8), 497-504

zorgvraag en stijgende zorgkosten, is het verschuiven van taken naar de eerste lijn. Binnen de oogzorg worden patiënten voor diagnose en advies door de eerstelijns optometrist gezien in plaats van de duurdere tweedelijns oogarts. Met specialistische kennis van het oog en de beschikking over moderne oogmeetinstrumenten zou de optometrist ook binnen de eerste lijn taken van de doorgaans drukbezette huisarts kunnen overnemen.

De optometrist vormt als oogzorgverlener een relatief jonge beroepsgroep. Vanaf 2000 wordt de optometrist onder artikel 34 van de Wet BIG genoemd, waarmee de titel van optometrist wettelijk beschermd is. Optometristen vervullen zowel een zorginhoudelijke als 'keten-organisatorische' rol binnen het oogzorgsysteem, zoals blijkt uit de definitie van deze beroepsgroep, vastgelegd in de Thesaurus Zorg en Welzijn: “(...) optometristen zijn (...) paramedici die oogafwijkingen onderzoeken, oogmetingen verrichten, oogziekten kunnen herkennen en mensen eventueel door kunnen verwijzen naar de huisarts, een oogarts of orthoptist; met name werkzaam in optiekzaken en ziekenhuizen"(noot ${ }^{1}$ ). Over het algemeen wordt gesteld dat de HBOopgeleide optometrist zich onderscheidt van de MBO-opgeleide opticien door hogere en bredere scholing, en door competenties en vaardigheden waarmee taken van huisartsen en oogartsen overgenomen zouden kunnen worden.

Herschikking van zorgtaken van de oogarts en de huisarts naar de optometrist wordt al langer bepleit door de Optometristen Vereniging Nederland.12 Er zijn echter nog geen onderzoeken waarin de (landelijke) omvang van het substitutiepotentieel van de optometrist is geschat. Er zijn wel lokale onderzoeken uitgevoerd, zoals in 2006 de studie van Prismant onder zeven optometristen in de regio Rijnmond (geen openbare publicatie). Hieruit bleek ten eerste dat het merendeel van patiënten op eigen initiatief naar een optometrist is gegaan, dan wel door een opticien of contactlensspecialist werd verwezen. Een kwart van de patiënten werd verwezen door een huisarts of een oogarts. Ten tweede bleek dat patiënten die door optometristen zijn onderzocht, relatief weinig naar andere zorgverleners werden verwezen: slechts $4 \%$ werd verwezen naar de huisarts en $21 \%$ naar de oogarts. Hieruit werd geconcludeerd dat er sprake is van een 'duidelijke filterfunctie' van optometristen. Het is echter een belangrijke beperking dat de omvang van de filterwerking op basis van deze gegevens moeilijk geschat kan worden, omdat de patiëntgegevens zijn verzameld over een relatief korte periode (enkele maanden in 2005) en alleen betrekking hadden op de regio Rijnmond. Daarnaast is niet gekeken naar patiënten die in dezelfde periode in dezelfde regio niet zijn verwezen. Nieuwe en aanvullende databronnen maken het mogelijk om binnen de Nederlandse oogzorg de omvang van de potentiële substitutie van zorgtaken door optometristen op nationaal niveau in te schatten. In dit artikel zal antwoord worden gegeven op de vraag: Hoe groot is, op basis van patiëntdata van eerstelijns optometriepraktijken en huisartspraktijken, het substitutiepotentieel van eerstelijns optometristen binnen het Nederlandse oogzorgsysteem in termen van patiëntverwijzingen tussen optometrist, huisarts en oogarts?

Achtereenvolgens wordt ingegaan op een methode om het substitutiepotentieel door de optometrist te schatten, de resultaten die dit oplevert, en de haken en ogen die aan dergelijke schattingen zitten. 
Hassel, D. van, Coops, A., Batenburg, R., Heus, P. Een meting van het substitutiepotentieel binnen de oogzorg. TSG: Tijdschrift voor Gezondheidswetenschappen: 2013, 91(8), 497-504

\section{METHODEN}

\section{Expertbeoordeling}

Voor het onderzoek is eerst een expertanalyse uitgevoerd. Optometristen en oogartsen uit het eigen netwerk van de auteurs is gevraagd een oordeel te geven over de substitueerbaarheid van een aantal oogaandoeningen, gebaseerd op de ICPCcodering die gebruikt wordt in Huisarts Informatiesystemen (HIS-en). Oogartsen die benaderd werden, werkten samen met optometristen zodat zij een goede inschatting van de substitueerbaarheid van oogaandoeningen konden maken. Uiteindelijk hebben vier optometristen (werkzaam in de eerste en tweede lijn) en twee oogartsen deelgenomen aan de expertbeoordeling. De experts gaven voor 68 oogaandoeningen aan of de optometrist deze aandoeningen net zo goed kan diagnosticeren en adviseren als de oogarts. Om de substitueerbaarheid van de aandoeningen te bepalen zijn de expertbeoordelingen onderling vergeleken, door in het bijzonder de beoordelingen van de oogartsen te vergelijken met die van de optometristen.

\section{Kernpunten}

- De optometrist kan naar schatting jaarlijks maximaal 207.000 patiënten met oogaandoeningen bedienen, die momenteel de huisarts consulteren.

- In potentie kan de optometrist 21.000 patiëntconsulten of verwijzingen naar de oogarts overnemen.

- Een kanttekening bij deze schattingen is onder meer dat slechts een beperkte lijst van substitueerbare oogaandoeningen werd beoordeeld door een beperkt aantal experts.

- Dit onderzoek laat zien hoe potentiële substitutie van de optometrist binnen de eerste lijn geanalyseerd en verkend kan worden.

\section{Analyse van twee datasets}

Daarnaast zijn voor het onderzoek twee datasets geanalyseerd. De eerste dataset betreft registratiegegevens van zeven optometristen, werkzaam in zeven optometriepraktijken verspreid over Nederland (Amsterdam, Zwolle, Utrecht, Rotterdam, Haarlem, Spijkernisse en Tilburg). In de dataset zijn over een gemiddelde periode van twee jaar (in 2009-2011) een aantal relevante gegevens bijgehouden, te weten de hoofdbevindingen van het optometrisch onderzoek, herkomst van de patiënt (indien verwezen, door wie) en eventuele verwijzingen naar oogarts en huisarts. De tweede dataset betreft gegevens van patiënten die met oogaandoeningen de huisarts in 2010 hebben bezocht. Deze gegevens zijn afkomstig uit het Landelijk Informatie Netwerk Huisartsenzorg (LINH), een panel-netwerk van huisartspraktijken dat opgezet en onderhouden wordt door het NIVEL(noot ${ }^{2}$ ). Hieruit is, gebaseerd op ruim 80 huisartspraktijken, het aantal huisartspatiënten per oogaandoening en het aantal patiënttoewijzingen naar oogarts en optometrist per oogaandoening afgeleid.

\section{Schatten van het substitutiepotentieel}

Voor een aantal relevante oogaandoeningen is een schatting gemaakt van het totaal aantal patiënten dat optometristen en huisartsen per jaar in Nederland zien. Bij deze schattingen is voor het landelijk aantal optometriepatiënten uitgegaan van 702(noot ${ }^{3}$ ) eerstelijnsoptometristen. Vervolgens is dit aantal vermenigvuldigd met het gemiddelde aantal patiënten dat jaarlijks met deze specifieke oogaandoening bij een 
Hassel, D. van, Coops, A., Batenburg, R., Heus, P. Een meting van het substitutiepotentieel binnen de oogzorg. TSG: Tijdschrift voor Gezondheidswetenschappen: 2013, 91(8), 497-504

optometrist komt. Dit gemiddelde aantal is afgeleid van de registratiecijfers van zeven optometristen hiervoor genoemd.

Om het landelijk aantal oogpatiënten dat de huisarts bezoekt te berekenen, is op basis van de LINH-data uitgegaan van het aantal (potentiële) patiënten in Nederland, te weten 16,5 miljoen inwoners. Dit aantal is gebruikt om het gemiddeld aantal patiënten in de LINH-praktijken dat voor specifieke oogaandoeningen de huisarts in 2010 heeft bezocht, te wegen naar nationaal niveau.

Op basis van de expertbeoordeling en beide genoemde databronnen zijn vervolgens twee vormen van substitutiepotentieel door de optometrist geschat, namelijk:

- Substitutie, doordat optometristen patiënten met oogproblemen minder vaak naar de oogarts verwijzen dan huisartsen;

- Substitutie, doordat patiënten met oogproblemen de optometrist voor onderzoek en advies consulteren en niet (of minder) de huisarts.

Het komt voor dat patiënten ook direct de oogarts consulteren, maar omdat dit relatief weinig patiënten betreft, laten we dit bij de substitutievormen buiten beschouwing.

\section{RESULTATEN}

\section{Expertbeoordeling van substitueerbare aandoeningen}

Op basis van een vergelijking van de expertbeoordelingen van twee oogartsen met die van vier optometristen konden de 68 ICPC-aandoeningen in de volgende vijf categorieën verdeeld worden.

Categorie 1:Zestien aandoeningen waarover de twee oogartsen en vier optometristen het volledig eens waren dat hiervoor substitutie door de optometrist mogelijk is.

Categorie 2 en 3: Tweeëntwintig aandoeningen waarover oogartsen en optometristen het gedeeltelijk eens waren dat substitutie door de optometrist mogelijk is, waarvan:

Zeventien aandoeningen waarvoor de twee oogartsen voor de substitueerbaarheid 'ja' en 'nee' invulden, terwijl de vier optometristen allen 'ja' invulden;

Vijf aandoeningen waarvoor de twee oogartsen 'ja' en 'nee' invulden, maar (opmerkelijk genoeg) de vier optometristen 'nee’ invulden.

Categorie 4: Achttien aandoeningen waarbij zowel de twee oogartsen als de vier optometristen aangaven dat substitutie niet mogelijk is.

Categorie 5: Twaalf aandoeningen waarover de oogartsen en optometristen het niet eens zijn of substitutie mogelijk is. De twee oogartsen vulden 'nee' in, terwijl de vier optometristen 'ja' invulden.

In tabel 1 staan de aandoeningen, verdeeld over de vijf genoemde categorieën, weergegeven.

Voor de analyse van het substitutiepotentieel door de optometrist is vervolgens uitgegaan van 33 aandoeningen waarvoor dit mogelijk wordt geacht, volgens zowel (één of beide) oogartsen als (alle vier de) optometristen: de 16 aandoeningen uit categorie 1 en de 17 aandoeningen uit categorie 2. 
Hassel, D. van, Coops, A., Batenburg, R., Heus, P. Een meting van het substitutiepotentieel binnen de oogzorg. TSG: Tijdschrift voor Gezondheidswetenschappen: 2013, 91(8), 497-504

Vervolgens is gekeken of deze 33 (ICPC-gecodeerde) aandoeningen in de dataset van de LINH-praktijken ook zo terug te vinden (c.q. gecodeerd) zijn in de dataset van de optometriepraktijken. Dan blijkt hoe slecht informatiesystemen in de zorg vergelijkbaar zijn als er geen uniforme standaard gebruikt wordt. Slechts acht van de 33 oogaandoeningen konden één op één gematched worden tussen de huisartsen - en optometristen-dataset. En dus blijft de analyse van het substitutiepotentieel beperkt tot deze acht aandoeningen die in tabel 2 geordend zijn naar de eerste twee 'substitutie-categorieën' uit tabel 1. Voor 25 ICPC-gecodeerde aandoeningen geldt helaas dat de oogartsen en optometristen het in het expertonderzoek wel (gedeeltelijk) eens waren dat deze substitutiepotentieel hebben, maar op basis van de beschikbare datasets geen schattingen kunnen worden gemaakt van hun substitutiepotentieel. We komen hier in de conclusie en discussie van dit artikel nog op terug.

\section{[TABEL 1 ][TABEL 2]}

\section{Schatten van het substitutiepotentieel}

In tabel 3 staan voor de overgebleven acht oogaandoeningen de aantallen patiënten die jaarlijks door de optometrist (gemiddeld over de periode 2009-2011) en de huisarts (2010) worden gezien, evenals de verwijspercentages onderling en richting de oogarts. Omdat het verwijspercentage van de optometrist naar huisarts zeer minimaal was, laten we dit buiten beschouwing.

Op basis van deze percentages en de naar landelijk niveau opgehoogde aantallen patiënten per dataset (zie hiervoor) zijn vervolgens de aantallen verwijzingen op landelijk niveau geschat. We illustreren die voor de aandoening 'myopie'. Hiervoor schatten we op jaarbasis:

dat 920 patiënten door de huisarts naar de optometrist worden verwezen (bijna 1,0\% van de 95.598 patiënten die met deze aandoening de optometrist bezochten), dat 774 patiënten door de huisarts naar de oogarts worden verwezen (bijna 12,6\% van de 6.156 patiënten die met deze aandoening de huisarts bezochten), dat 5.211 patiënten door de optometrist naar de oogarts worden verwezen (bijna 5,5\% van de 95.598 patiënten die met deze aandoening de optometrist bezochten). Om nu het substitutiepotentieel op basis van deze schattingen te berekenen, maken we onderscheid tussen de twee vormen van substitutie zoals hiervoor gedefinieerd.

\section{[TABEL 3]}

\section{Substitutie 1: minder verwijzingen naar de oogarts}

Substitutie in de eerste verschijningsvorm treedt op als de huisarts patiënten naar de eerstelijns optometrist verwijst in plaats van de (duurdere) tweedelijns oogarts, en vervolgens de optometrist minder vaak, minder snel of met meer voorinformatie naar de oogarts verwijst dan de huisarts. In die gevallen zouden er dankzij de optometrist in potentie meer patiënten in de eerste lijn afgehandeld kunnen worden. Het verschil in verwijspercentage naar de oogarts, tussen optometrist en huisarts, is voor deze vorm van substitutie dus bepalend. Zoals uit tabel 3 valt af te lezen, geldt voor zes van de acht geselecteerde aandoeningen dat de optometrist een lager verwijspercentage dan de huisarts heeft. Voor drie oogaandoeningen is het verschil 
Hassel, D. van, Coops, A., Batenburg, R., Heus, P. Een meting van het substitutiepotentieel binnen de oogzorg. TSG: Tijdschrift voor Gezondheidswetenschappen: 2013, 91(8), 497-504

10\% of meer: presbyopie (11\%), refractie afwijking(en) (10\%) en astigmatisme (10\%). Voor de aandoeningen hypermetropie en insufficiënte traanfilm/tranende ogen geldt dat de huisarts net iets minder of even vaak verwijst naar de oogarts. Deze aandoeningen worden voor de schatting van dit substitutiepotentieel buiten beschouwing gelaten.

Om de omvang en opbouw van dit substitutiepotentieel inzichtelijk te maken is figuur 1 opgesteld. De figuur laat zien hoe patiëntenstromen voor de geselecteerde zes oogaandoeningen tezamen zich verdelen tussen huisarts, optometrist en oogarts. Omdat we ervan uit kunnen gaan dat deze vorm van substitutie niet gelijk of volledig zal optreden, wordt het effect van potentiële substitutie uitgedrukt voor vier verschillende situaties:

- Scenario 0; de situatie waarin er géén sprake is van substitutie en patiënten zich over huisarts, optometrist en oogarts verdelen, zoals we hiervoor hebben geschat op basis van de LINH- en optometristen-datasets;

- Scenario 1; de situatie waarin er sprake is van 'maximale' substitutie, waarin $100 \%$ van de huisartspatiënten met de betreffende aandoening naar de optometrist en niet naar de oogarts wordt verwezen;

- Scenario 2; de situatie waarin er sprake is van 'halve' substitutie, waarin 50\% van de huisartspatiënten met de betreffende aandoening naar de optometrist en niet naar de oogarts wordt verwezen;

- Scenario 3; de situatie waarin er sprake is van 'beperkte' substitutie, waarin $10 \%$ van de huisartspatiënten met de betreffende aandoening naar de optometrist en niet naar de oogarts wordt verwezen.

Voor scenario's 1, 2 en 3 staat onder de stroomdiagrammen de omvang van het totale geschatte substitutiepotentieel weergegeven. Dit getal is berekend door het aantal naar-de-oogarts-verwezen-patiënten in de scenario's 1 , 2 en 3 te vergelijken met het aantal in scenario 0 (de 'uitgangssituatie'). In scenario 1 zou de optometrist bijna zes maal zoveel patiënten van de huisarts doorverwezen krijgen als in scenario 0 , waardoor 21.000 patiënten meer binnen de eerste lijn zouden worden behandeld. Wanneer de helft van de patiënten door de huisarts naar de optometrist zou worden doorverwezen, dan zou dit substitutiepotentieel 11.000 patiënten zijn. Bij het derde scenario van beperkte substitutie gaat het om 2.000 patiënten die in de eerste en niet in de tweede lijn behandeld worden.

\section{[FIGUUR 1 ]}

\section{Substitutie 2: minder patiënten naar de huisarts}

De tweede vorm van substitutie gaat uit van het feit dat zowel de huisarts als de optometrist direct toegankelijk is voor patiënten. De optometrist zal doorgaans uitgebreider en gerichter oogonderzoek uitvoeren dan de huisarts. Als de optometrist ten minste even goed patiënten met een substitueerbare oogaandoening onderzoekt en adviseert als de huisarts, dan kan dit in potentie de patiëntenstroom naar de huisarts geheel of gedeeltelijk 'afvangen'. Uiteraard is hiervoor bepalend dat de patiënt voor deze oogaandoeningen de optometrist en niet de huisarts zal consulteren. Om ook de omvang van deze vorm van potentiële substitutie te visualiseren, is figuur 2 opgesteld. Patiëntenstromen en schattingen worden wederom weergegeven voor vier scenario's waarmee het effect getrapt (van $0 \%$ naar 100\%, 50\% en $10 \%$ substitutie) kan worden bekeken. Uitgegaan is van alle acht eerder geselecteerde 
Hassel, D. van, Coops, A., Batenburg, R., Heus, P. Een meting van het substitutiepotentieel binnen de oogzorg. TSG: Tijdschrift voor Gezondheidswetenschappen: 2013, 91(8), 497-504

oogaandoeningen waarover oogartsen en optometristen het (gedeeltelijk) eens waren dat deze substitueerbaar zijn.

De schatting voor scenario 0 ('huidige situatie') is dat 214.000 patiënten met deze oogaandoeningen direct de huisarts consulteren. Wanneer deze groep in zijn totaliteit de optometrist zou consulteren, dan zou het substitutiepotentieel zo'n 207.000 patiënten zijn (rekening houdend met 7.000 patiënten die toch via de huisarts bij de optometrist terecht komen) . Bij scenario 2 gaat het om ruim 103.000 patiënten, bij scenario 3 (10\% van de patiënten gaat voortaan rechtstreeks naar de optometrist in plaats van de huisarts) gaat het om een substitutiepotentieel van ruim 21.000 patiënten.

\section{[FIGUUR 2]}

\section{CONCLUSIE EN DISCUSSIE}

Er zijn niet eerder schattingen gemaakt van het substitutiepotentieel van de optometrist binnen de Nederlandse oogzorg. Dit onderzoek heeft op basis van (geaggregeerde) patiëntdata van optometriepraktijken en huisartspraktijken laten zien hoe dit voor deze beroepsgroep op twee manieren geschat kan worden. Bronnen vormden gegevens uit de periode 2009-2011 van zeven optometriepraktijken die landelijk verspreid zijn over Nederland, en gegevens uit 2010 van ruim 80 huisartspraktijken die deel uitmaken van het Landelijk Informatie Netwerk Huisartsenzorg (LINH) van het NIVEL. Voor een beperkt aantal oogaandoeningen konden beide datasets met elkaar vergeleken worden.

In het onderzoek is ten eerste ingeschat wat de jaarlijkse effecten zouden zijn van het feit dat de optometrist bij bepaalde oogaandoeningen minder patiënten naar de oogarts verwijst dan de huisarts. Dit substitutiepotentieel is berekend voor zes oogaandoeningen waarover een tweetal oogartsen en vier optometristen het eens waren dat hiervoor substitutiepotentieel door de optometrist mogelijk is. Het gaat om refractie afwijkingen, presbyopie, myopie, astigmatisme, cataract/staar en maculadegeneratie. Het substitutiepotentieel had over meer aandoeningen berekend kunnen worden, maar niet alle aandoeningen bleken in de onderzochte optometristen- en LINH-dataset op een zelfde manier gecodeerd te zijn. Wanneer de zes aandoeningen samen worden genomen, kan geschat worden dat de optometrist op landelijk niveau jaarlijks 21.000 patiënten extra in de eerste lijn kan 'houden', wanneer sprake zou zijn van maximale substitutie. Wanneer alleen de helft van de huisartspatiënten bij de optometrist terecht zou komen, dan zou het substitutiepotentieel jaarlijks 11.000 patiënten zijn, terwijl dit bij 10\% uitkomt op 2.000 patiënten.

Een tweede vorm van substitutie is ingeschat op basis van het gegeven dat de optometrist direct toegankelijk is voor patiënten. Huisartsconsulten zouden hiermee uitgespaard kunnen worden, omdat oogproblemen even goed en afdoende onderzocht en geadviseerd kunnen worden in de optometriepraktijk. Dit substitutiepotentieel is over acht oogaandoeningen geschat; dezelfde zes als voor de eerste vorm van substitutie, plus een tweetal aandoeningen waar de twee oogartsen en vier optometristen het ook (gedeeltelijk) eens waren dat hiervoor substitutie door de optometrist mogelijk is, te weten insufficiënte traanfilm /tranende ogen en hypermetropie. De schatting is dan dat de optometrist, op landelijk niveau, jaarlijks maximaal 207.000 patiënten af kan handelen die anders geconsulteerd zouden zijn 
Hassel, D. van, Coops, A., Batenburg, R., Heus, P. Een meting van het substitutiepotentieel binnen de oogzorg. TSG: Tijdschrift voor Gezondheidswetenschappen: 2013, 91(8), 497-504

door de huisarts. Bij de helft van de betreffende huisartspatiënten komt dit aantal uit op potentieel 103.000 patiënten per jaar en bij 10\% op potentieel 21.000 patiënten. Substitutie krijgt in toenemende mate aandacht van de overheid en zorgverzekeraars, met name omdat het kan leiden tot kostenbesparingen. Dit onderzoek is alleen gericht op het schatten van het substitutiepotentieel en niet op de kosten die daarmee mogelijk bespaard kunnen worden. Voor dat laatste zouden de tarieven voor een huisartsconsult, een oogheelkundig DBC en een consult door de optometrist goed vergeleken moeten worden, rekening houdend met de duur en het verrekeningsmodel van de consultatie. Op basis van dit onderzoek kan hier weinig over gezegd worden, daarbij aangetekend dat tarieven van de betrokken (para)medici niet bepalend zijn voor de totale zorgkosten. Bij het inschatten van besparingen door subsitutie moet ook rekening gehouden worden met andere factoren. Zo kan het zijn dat door substitutie nieuwe disciplines, zoals de optometrist, met hun kennis, vaardigheden en instrumenten uitgebreidere zorg mogelijk maken. Daardoor zou de kwaliteit omhoog kunnen gaan, maar zouden ook de kosten kunnen stijgen. Eveneens kan voor de huisartsen en oogartsen gelden dat de vrijgekomen tijd door minder patiënten, wordt benut met uitgebreidere zorg en een langere consultduur per patiënt. Toekomstig onderzoek moet uitwijzen of de inzet van andere disciplines zal leiden tot suppletie in plaats van substitutie.14,15 Een ander onbedoeld neveneffect die bij substitutie een rol kan spelen, is dat patiënten versnipperd raken over verschillende disciplines.16 De toegevoegde waarde van de huisarts als generalist kan daarmee onder druk komen te staan, aangezien deze het beste op de hoogte is van de algehele gezondheidstoestand van de patiënt en ook in staat is om aandoeningen in hun onderlinge samenhang te herkennen.17

De aantallen die in dit onderzoek geschat zijn, moeten met voorzichtigheid worden geïnterpreteerd. Allereerst is bij de substitueerbaar veronderstelde oogaandoeningen ervan uitgegaan dat de patiënten die bij de huisarts komen niet verschillen van de optometrie-patiënten, althans in de zwaarte van hun oogaandoening. Het kan echter zijn dat er toch een zekere mate van zelfselectie plaatsvindt, en patiënten met complexe en zwaardere oogaandoeningen de huisarts consulteren. In dat geval is het niet verwonderlijk dat het percentage oogartsverwijzingen bij de huisarts hoger is dan bij de optometrist. In hoeverre dit een rol speelt kunnen we op basis van de data van dit onderzoek niet zeggen.

Er gelden ten tweede beperkingen wat betreft de omvang, representativiteit en vergelijkbaarheid van de patiënten-datasets én de gehanteerde aannamen voor de ophogingen naar landelijk niveau. Ten derde is slechts een beperkte consultatie gedaan onder twee oogartsen en vier optometristen om te bepalen welke oogaandoeningen in potentie substitueerbaar zijn door de optometrist binnen de oogzorg en welke niet. Twee aanbevelingen voor verder onderzoek komen hieruit voort. Het is belangrijk oogaandoeningen in een vervolgonderzoek breder en uitgebreider te beoordelen. Meer beoordelaars en meer uitgebreide casuïstiek is gewenst om de 'potentieel/theoretische' substitueerbaarheid van (eenduidig gedefinieerde) oogaandoeningen zo betrouwbaar en valide mogelijk te bepalen. Daarnaast is het van belang om de vergelijking van datasets te verbeteren door aandoeningenclassificaties te hanteren die zowel binnen optometriepraktijken, als huisartspraktijken en tevens ziekenhuizen en oogklinieken te matchen zijn. Ondanks deze beperkingen, heeft het onderzoek in conceptuele zin een bijdrage geleverd aan hoe potentiële substitutie van de optometrist binnen de eerste lijn 
Hassel, D. van, Coops, A., Batenburg, R., Heus, P. Een meting van het substitutiepotentieel binnen de oogzorg. TSG: Tijdschrift voor Gezondheidswetenschappen: 2013, 91(8), 497-504

geanalyseerd en verkend kan worden. In een tijd waarin de druk op kostenbeheersing in de zorg steeds groter wordt, is een verantwoorde en kosteneffectieve verschuiving van verrichtingen van de tweede naar de eerste lijn van groot belang. Ook in de oogzorg speelt dit. De toenemende druk op de huisartsenzorg, het dreigend tekort aan oogartsen en zorgverzekeraars die steeds kritischer gespecialiseerde oogzorg inkopen, dragen hier aan bij. Daarbij is niet alleen meer aandacht voor het substitutiepotentieel van de optometrist belangrijk, maar gaat het ook om de concrete potentiële kostenbesparingen die de optometrist kan opleveren.

\section{LITERATUUR}

1. Nederlandse zorgautoriteit (NZa). Advies taakherschikking in de tweedelijns somatische zorg en curatieve geestelijke gezondheidszorg. Utrecht: NZa, 2012.

2. Raad voor de Volksgezondheid en Zorg (RVZ). Taakherschikking in de gezondheidszorg. Zoetermeer: RVZ, 2002.

3. Berg MJ van den, Koopmanschap MA, Bakker DH de, Verheij RA. Samenwerking en substitutie in Gezondheidscentrum West. Evaluatie van de eerste ervaringen met geïntegreerde eerstelijnszorg volgens het Menzis-model. Utrecht: NIVEL, 2007.

4. Leemrijse CJ, Swinkels ICS, Pisters MF, Bakker D de, Veenhof C. Directe toegang fysiotherapie: de keus is aan de patiënt. Ned Tijdschr Fysiotherapie 2008;118;3:62-7

5. Hansen J, Maat M van der en Batenburg R. De eerstelijns mondzorg door consumenten bekeken. Utrecht: NIVEL, 2010.

6. Jerkovic K. The Relation between Profession Development and Job (Re)Design: The Case of Dental Hygiene in the Netherlands. Proefschrift. Groningen: University of Groningen, 2012.

7. Jerkovic $K$, Offenbeek MAG van, Schans $C P$ van der. Taakherschikking in de Nederlandse mondzorg en de werktevredenheid van mondhygiënisten. Nederlands Tijdschrift Tandheelkunde 2010;117:289-294. 8. Capaciteitsorgaan. Capaciteitsplan 2007: Voor de Medische Vervolgopleidingen Jeugdgezondheidszorg, Utrecht: Capaciteitsorgaan, 2007.

8. Capaciteitsorgaan. Capaciteitsplan 2007: Voor de Medische Vervolgopleidingen Jeugdgezondheidszorg, Utrecht: Capaciteitsorgaan, 2007

9. Bal R, Bont A de. Taakherschikking en ICT in de zorg. In Jos de Haan \& Lambert van der Laan (Red.). Kennis in Netwerken: Jaarboek ICT en Samenleving 2005. Amsterdam: Boom 2005; 113-126.

10. Digibron. Tekort aan oogartsen gaat zich wreken: wachtlijsten zullen groeien en vooral mensen met suikerziekte zijn daarvan de dupe. http://www.digibron.nl/search/share.jsp?uid $=00000000012 \mathrm{de} 5 \mathrm{ec} 8393459 \mathrm{ac} 630 \mathrm{be} 04 \&$ sourceid=1011 (geraadpleegd op 21 augustus 2013), 1995.

11. Bussemakers $\mathrm{H}$, Treskens DJ, Bleeker JC, Klomp HJ. Optometristen in de oogheelkundige praktijk. Med Contact 2005;60:44.

12. Optometristen Vereniging Nederland (OVN). Beleidsplan 2011-2014. Weert: OVN, 2011.

13. Amelsfoort J van, Kauffman K, Peters F. De arbeidsmarkt van optometristen en orthoptisten. Nijmegen: Kenniscentrum Beroepsonderwijs Arbeidsmarkt, 2010.

14. Heiligers PJM, Noordman J, Korevaar JC et al. Praktijkondersteuners in de huisartspraktijk (POH's), klaar voor de toekomst? Utrecht: NIVEL, 2012.

15. Nederlandse zorgautoriteit (Nza). Advies substitutie. Huisartsenzorg en ziekenhuiszorg op de juiste plek. Utrecht: Nza, 2012.

16. Ter Brugge, A., Helsloot RSM, Veld JC in 't. Ruim baan voor de praktijkverpleegkundige. Med Contact 2006;61;:371.

17. Nederlands Huisartsengenootschap (NHG). NHG-Standpunt kernwaarden huisartsgeneeskunde: generalistisch, persoonsgericht en continue. Utrecht: NHG, 2011. 
Hassel, D. van, Coops, A., Batenburg, R., Heus, P. Een meting van het substitutiepotentieel binnen de oogzorg. TSG: Tijdschrift voor Gezondheidswetenschappen: 2013, 91(8), 497-504

\author{
Noten \\ a Zie http://www.thesauruszorgenwelzijn.nl/optome- tristen.htm \\ b Zie http://www.nivel.nl/linh-intro \\ c $85 \%$ van de 826 optometristen in Nederland werkt eind 200913 in de eerste lijn. \\ d Een patie“nt met refractie afwijkingen kan op verschil- lende afstanden geen scherp \\ beeld vormen. Specifieke vormen van refractie afwijkingen zijn presbyopie \\ (ouderdomsverziendheid), hypermetropie (verziend- heid), myopie (bijziendheid) en \\ astigmatisme (cilin- drische afwijking). Patie"nten met cataract/staar heb- ben een \\ vertroebeling van de ooglens, terwijl macula degeneratie zorgt voor vermindering \\ van het zicht door slijtage van het centrale deel van het netvlies. (zie \\ http://www.oogartsen.nl/homepage/).
}

\title{
TABELLEN EN FIGUREN
}

Tabel 1 Oogaandoeningen naar vijf niveaus van overeenkomst tussen het oordeel van oogartsen en optometristen op de vraag of substitutie naar de optometrist mogelijk is

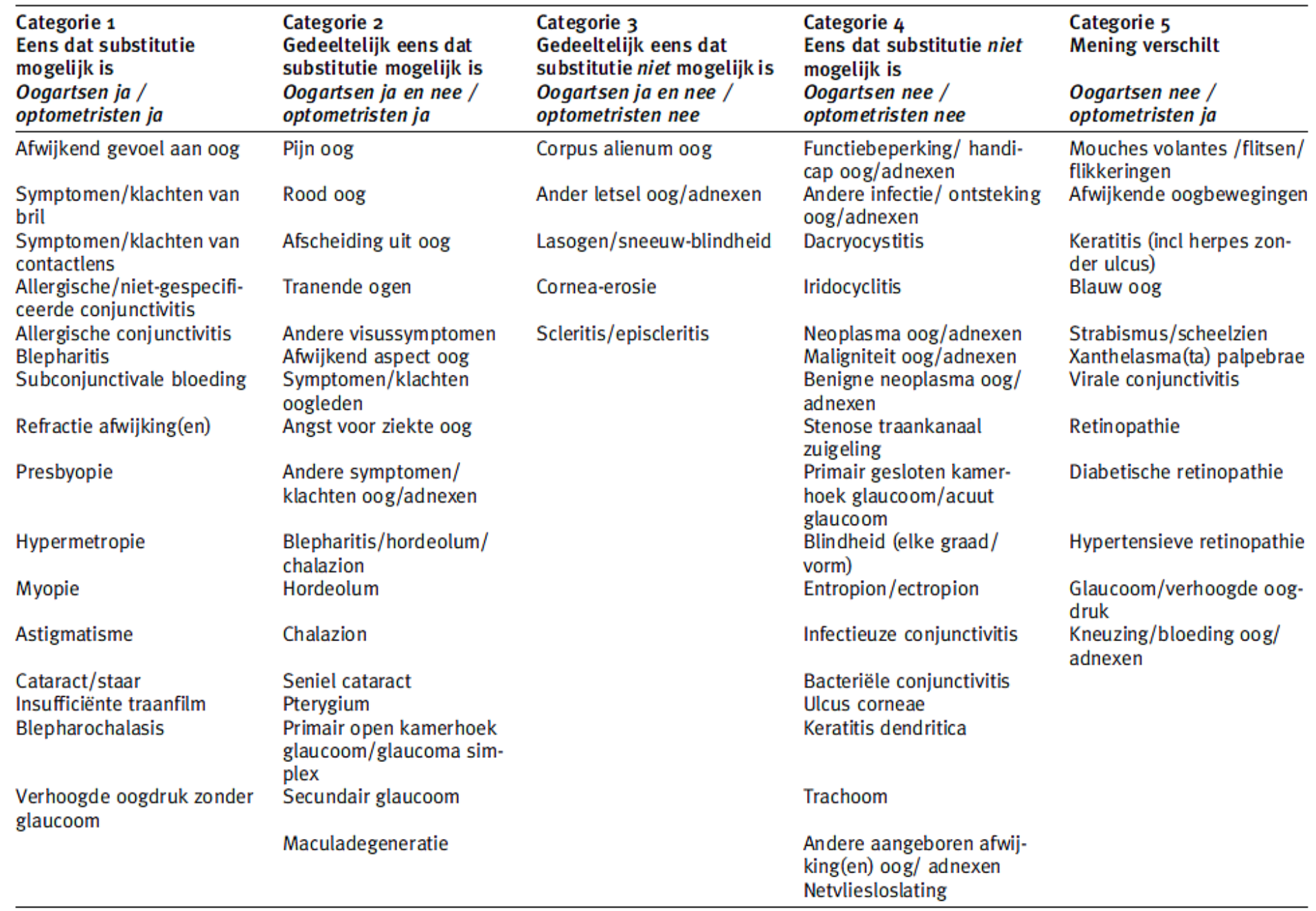


Hassel, D. van, Coops, A., Batenburg, R., Heus, P. Een meting van het substitutiepotentieel binnen de oogzorg. TSG: Tijdschrift voor Gezondheidswetenschappen: 2013, 91(8), 497-504

Tabel 2 Acht substitueerbare aandoeningen(noot d) waarvoor ICPCcodering in de LINH-dataset en aandoening-codering in de optometristen-dataset overeenkomen, naar mate van overeenkomst tussen oogartsen en optometristen ten aanzien van substitueerbaarheid

\begin{tabular}{ll}
\hline Substitutie-categorie & Aandoeningen \\
\hline Categorie 1 (oogarts en optometrist zijn & Refractie afwijkingen \\
het eens dat substitutie mogelijk is) & Presbyopie \\
& Hypermetropie \\
& Myopie \\
& Astigmatisme \\
& Cataract/staar
\end{tabular}

Categorie 2 (oogarts en optometrist zijn het gedeeltelijk eens dat substitutie Insufficiënte traanfilm \& mogelijk is)

Tranende ogen ${ }^{a}$

${ }^{a}$ De ICPC-aandoeningen insufficiënte traanfilm en tranende ogen zijn samengevoegd om een match te kunnen maken met de aandoeningenclassificatie uit de optometristendataset.

Tabel 3 Schatting van de jaarlijkse aantallen patiënten die de huisarts en optometrist bezoeken voor acht substitueerbare oogaandoeningen, en hun verwijspercentages naar de oogarts

\begin{tabular}{|c|c|c|c|c|c|c|}
\hline & $\begin{array}{l}\text { Aantal patiënten } \\
\text { bij huisarts }^{\mathrm{a}}\end{array}$ & $\begin{array}{l}\text { Aantal patiënten } \\
\text { bij optometrist }\end{array}$ & $\begin{array}{l}\text { Verwijzing van } \\
\text { huisarts naar } \\
\text { optometrist } \\
\text { gemiddeld per } \\
\text { optometrist(\%) }\end{array}$ & $\begin{array}{l}\text { Verwijzing van } \\
\text { huisarts naar oog- } \\
\text { arts gemiddeld } \\
\text { per huisarts (\%) }\end{array}$ & $\begin{array}{c}\text { Verwijzing van } \\
\text { optometrist } \\
\text { naar oogarts } \\
\text { gemiddeld per } \\
\text { optometrist }(\%)^{b}\end{array}$ & $\begin{array}{c}\text { Verschil verwij- } \\
\text { zing naar oogarts, } \\
\% \text { optometrist } \\
\text { t.o.v. huisarts }\end{array}$ \\
\hline Refractie afwijking(en) & 59.344 & 233.898 & $1,3 \%$ & $15,1 \%$ & $4,9 \%$ & $-10,2 \%$ \\
\hline Presbyopie $c$ & 1.069 & 5.090 & $0,0 \%$ & $13,8 \%$ & $2,7 \%$ & $-11,1 \%$ \\
\hline Hypermetropie $\boldsymbol{c}$ & 2.949 & 115.470 & $1,6 \%$ & $3,8 \%$ & $4,5 \%$ & $0,7 \%$ \\
\hline Myopie $c$ & 6.156 & 95.598 & $1,0 \%$ & $12,6 \%$ & $5,5 \%$ & $-7,1 \%$ \\
\hline Astigmatisme $c$ & 958 & 15.681 & $1,4 \%$ & $15,4 \%$ & $5,1 \%$ & $-10,3 \%$ \\
\hline Cataract/staar & 90.970 & 41.684 & $0,9 \%$ & $12,2 \%$ & $4,1 \%$ & $-8,1 \%$ \\
\hline Maculadegeneratie & 11.795 & 4.823 & $1,3 \%$ & $12,5 \%$ & $6,6 \%$ & $-5,9 \%$ \\
\hline $\begin{array}{l}\text { Insufficiënte traanfilm/ } \\
\text { tranende ogen }\end{array}$ & 40.435 & 7.422 & $2,7 \%$ & $3,8 \%$ & $3,8 \%$ & $0,0 \%$ \\
\hline Totaal & 213.676 & 519.666 & $1,3 \%$ & $11,3 \%$ & $4,8 \%$ & $-6,5 \%$ \\
\hline
\end{tabular}

${ }^{a}$ Gebaseerd op de LINH-dataset uit 2010

b Gebaseerd op de optometristen-dataset, waarin over de periode 2009-2011 gegevens zijn verzameld

' Betreft de facto een specifieke vorm van refractieafwijking. Wanneer de diagnose refractieafwijking is geregistreerd maar de specifieke vorm on bekend was, is dit alleen onder de (algemene) noemer 'refractieafwijking' geregistreerd. 
Hassel, D. van, Coops, A., Batenburg, R., Heus, P. Een meting van het substitutiepotentieel binnen de oogzorg. TSG: Tijdschrift voor Gezondheidswetenschappen: 2013, 91(8), 497-504

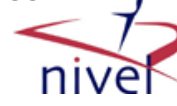

Figuur 1 Schatting van de jaarlijkse patiëntstromen (afgerond op duizendtallen) voor zes substitueerbare oogaandoeningen tussen huisarts, optometrist en oogarts in vier scenario's, en de inschatting van het substitutiepotentieel waarbij patiënten door de huisarts niet naar de oogarts maar naar de optometrist worden verwezen.

Scenario 0: Huidige situatie

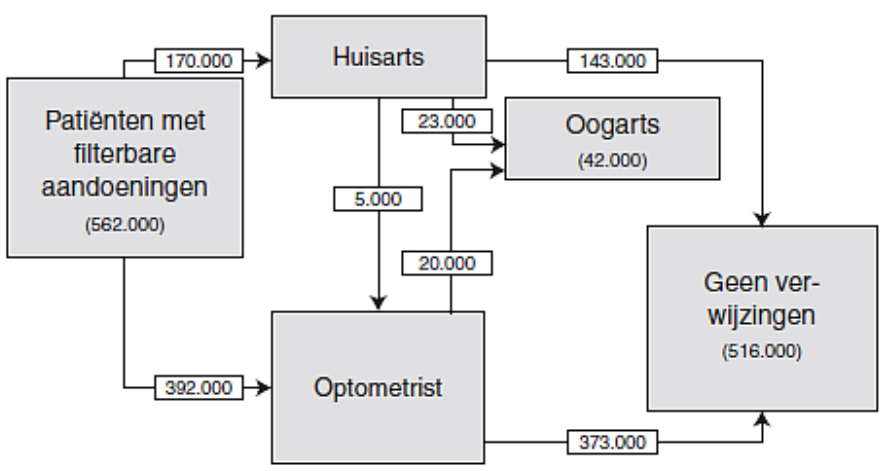

Scenario 2: 50\% van alle huisartspatienten gaan i.p.v. de oogarts naar de optometrist

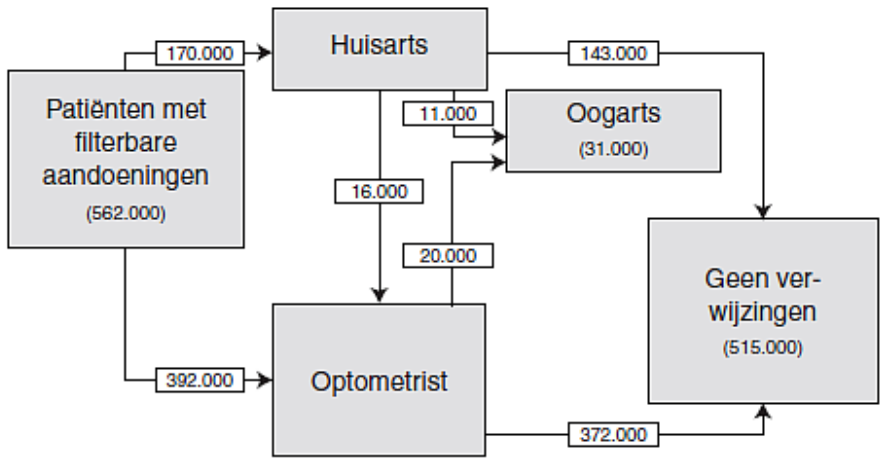

Substitutlepotentleel: 11.000 patlenten
Scenario 1: $100 \%$ van alle huisartspatienten gaan i.p.v. de oogarts naar de optometrist

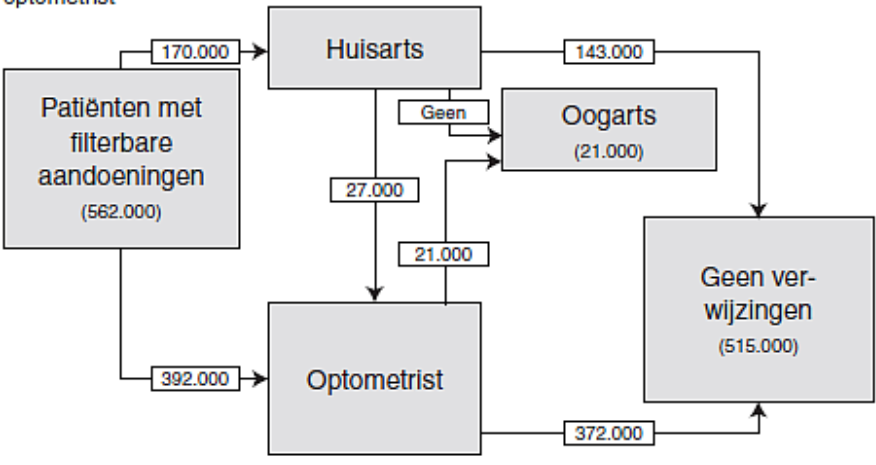

Substitutlepotentleel: 21.000 patlenten

Scenario $3: 10 \%$ van alle huisartspatienten gaan i.p.v. de oogarts naar de optometrist

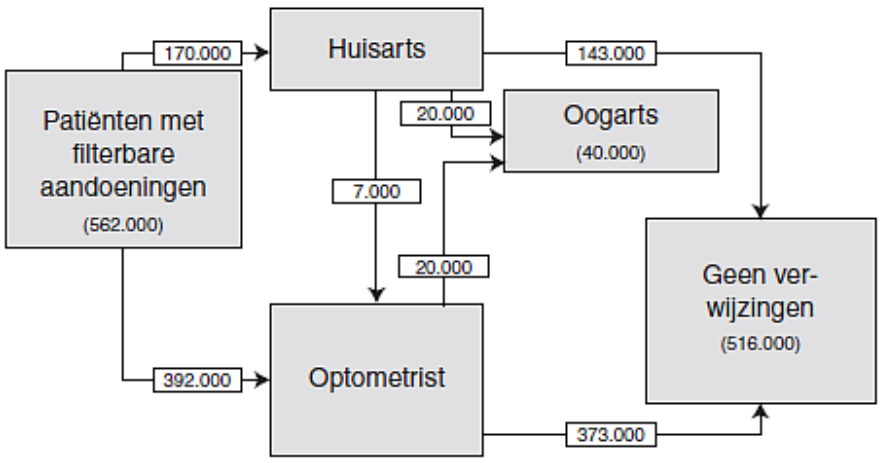

Substitutlepotentleel: 2.000 patienten 
Hassel, D. van, Coops, A., Batenburg, R., Heus, P. Een meting van het substitutiepotentieel binnen de oogzorg. TSG: Tijdschrift voor Gezondheidswetenschappen: 2013, 91(8), 497-504

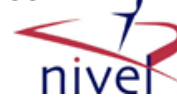

Figuur 2 Schatting van de jaarlijkse patiëntstromen (afgerond op duizendtallen) voor acht substitueerbare oogaandoeningen tussen huisarts, optometrist en oogarts in vier scenario's, en de inschatting van het substitutiepotentieel waarbij patiënten niet direct de huisarts maar de optometrist consulteren.

Scenario 0: Huidige situatie

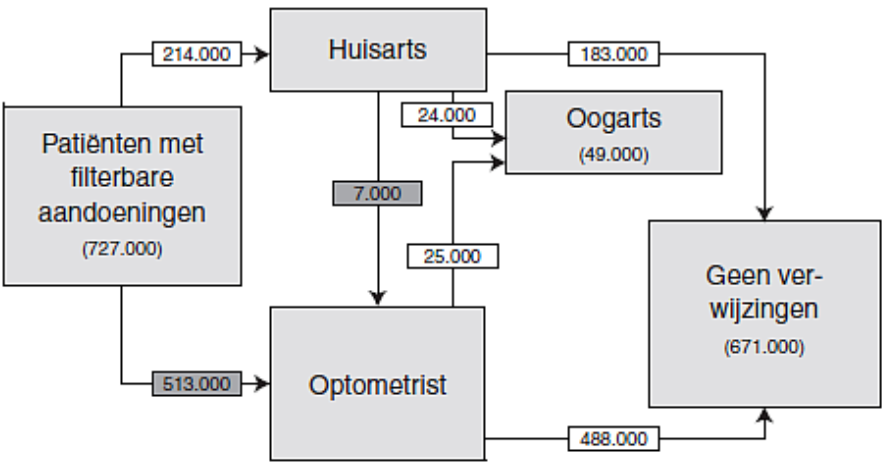

Scenario 2: $50 \%$ van alle huisartspatiēnten gaat direct naar de optometrist

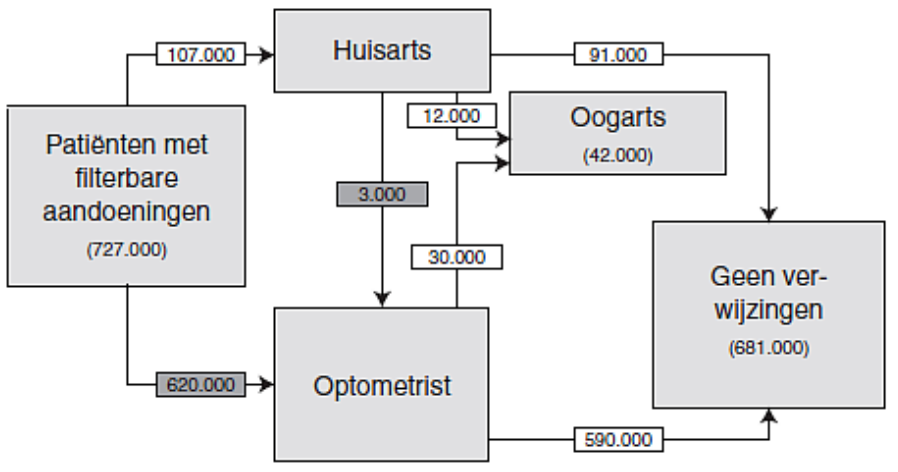

Substitutlepotentleel: 103.000 patienten
Scenario 1: 100\% van alle huisartspatiēnten gaat direct naar de optometrist

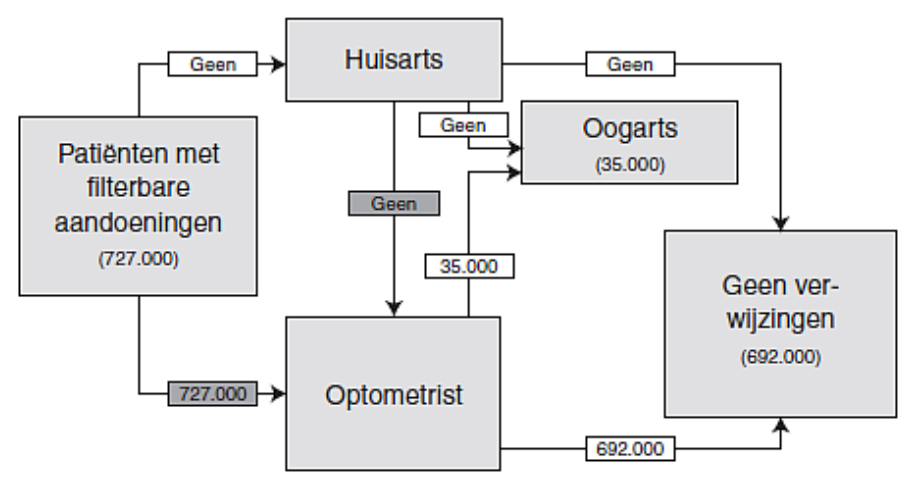

Substitutlepotentleel: 207.000 patienten

Scenario 3: 10\% van alle huisartspatiënten gaat direct naar de optometrist

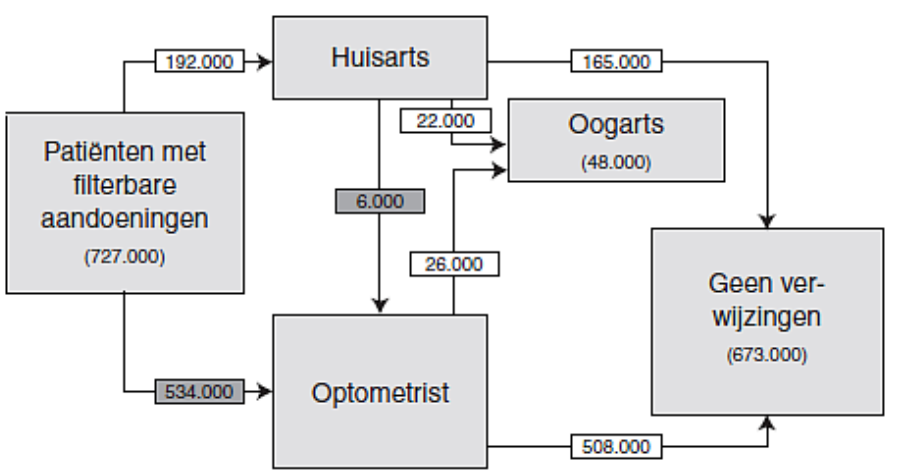

Substitutlepotentleel: 21.000 patienten 